\title{
Telemental health in rural correctional institutions
}

\author{
Edward Kaftarian \\ Orbit Health Telepsychiatry, Encino, CA, USA \\ Correspondence to: Edward Kaftarian, MD. CEO, Orbit Health Telepsychiatry, 17412 Ventura Blvd, \#1000, Encino, CA 91316, USA. \\ Email: edward@orbithealth.com.
}

Received: 19 August 2019; Accepted: 02 December 2019; Published: 05 July 2020.

doi: 10.21037/mhealth.2019.12.05

View this article at: http://dx.doi.org/10.21037/mhealth.2019.12.05

\section{A desperate need for mental health treatment}

Mental illness is common in the jail and prison populations, and over the last several decades, correctional facilities have become the de facto asylums. There are nearly 400,000 people with mental illness incarcerated in the United States, which is more than 10 times the amount of people in our State Hospitals (1). In fact, the Los Angeles County Jail, Cook County Jail in Chicago, and Riker's Island Jail in New York each hold more individuals with mental illness than any other psychiatric hospital in the United States (1). With a rising population of people with mental illness who are currently incarcerated, there is an increasing need for mental health treatment.

Inmates with mental illness pose a greater threat to safety and security of a facility, and they are twice as likely to be charged with rule violations (1). Untreated mental illness also poses a threat to society as inmates are more likely to reoffend if they are not stabilized in their mental illness prior to being released. Effective treatment of offenders with mentally illness is an essential component of their reintegration into society, and it is imperative that inmates with mental illness are given adequate access to mental health professionals while they are incarcerated. Beyond the ethical and practical imperatives to provide care, inmates have a constitutional right to mental health treatment as decided by the Supreme Court in the case of Estelle v. Gamble (2).

\section{A shortage of providers}

There are 1,719 state prisons, 109 federal prisons, 1,772 juvenile correctional facilities, 3,163 local jails, and 80 Indian Country jails as well as military prisons, immigration detention facilities, civil commitment centers, state psychiatric hospitals, and prisons in the United States and territories (3). Approximately 70 percent of prisons were built in rural areas (4) and most nonmetropolitan counties (65\%) do not have a psychiatrist and almost half of nonmetropolitan counties (47\%) do not have a psychologist (5). Thus, there is a striking geographic disparity between the location of inmates with mental illness and mental health professionals that can help them.

Furthermore, many providers are reluctant to take a job inside a prison or jail due to a variety of reasons, most pressing is the concern over personal safety. The environment itself can be intimidating and off-putting including the brutalistic architecture, dim lighting, and often unclean environment, working within correctional facilities can be an unpleasant experience. As a result, correctional facilities often run on a deficit of mental health staff. Recruitment is an ongoing logistical issue that has great impact on the overall function of correctional mental health programs.

\section{The telemental health staffing solution}

Telemental health is the delivery of mental health services remotely using videoconferencing technology. Regardless of whether the mental health providers are State/Federal employees or contract workers, it can be an effective solution to staffing shortages. Telemental health allows mental health professionals sitting in their urban and suburban offices to provide treatment to inmates located in remote rural facilities. Videoconferencing technology allows these providers to traverse great distances virtually, without having to commute, and the recruitment pool for correctional facilities is greatly expanded. Furthermore, telemental health takes away most every safety concern, 
as the clinician and patient are not in the same physical location. An added benefit of telemental health is that clinicians are able to free themselves from the culture of working within the prison walls. Sitting in the comfort of their own office, they are able to control for cleanliness and enjoy amenities not accessible to those working within the secure perimeter of the facility.

\section{Avoiding transport}

Inmates are often transported for mental health care due to a lack of appropriate mental health services at the originating facility. Transporting inmates from one rural facility to another can be an expensive proposition. Facilities may be hundreds of miles from each other and typical inmate transports include at least two officers often accompanied by medical staff such as a nurse. Transporting an inmate also increases the risk to the public as the inmate has a greater chance of escape while in transit.

Telemental health offers a way for the inmate to obtain the mental health care needed while remaining at his/ her facility. For example, a patient who goes into a crisis can potentially be stabilized by a psychiatrist via remote videoconference while the inmate remains in the facility. Inmates may be transferred from one correctional facility to another for other reasons beyond need for mental health services including:

(I) Discharge planning and coordination for inmate release that occurs closer to their home;

(II) Medical issues that cannot adequately be addressed by the facility;

(III) Safety and security of the patient and the facility, especially due to special circumstances such as gang affiliation, sex offenses, race, gender identity, or sexual preference.

Historically, when an inmate transfers from one rural facility to another, their treatment team and services can be disrupted. Introducing new members of a treatment team can result in a loss of continuity of care and a need to reestablish trust in the therapeutic relationship. Telemental health allows the treatment team to transition virtually with the patient as they transfer from one rural facility to another.

\section{Reduced operational costs}

Operating jails and prisons is complicated, given safety and security protocols as well as managing the health and welfare of a population prone to disease and violence. In addition, there is the cost of housing, furniture, and equipment. Getting staff and supplies to build and run facilities can be an additional challenge. Telemental health relieves some of the need for office space and equipment, as the clinicians work remotely in their own offices and are out of the way of the facility. This allows the custody officers to focus on their job of managing the movement of inmates and securing the facility. Furthermore, since staff are out of harm's way, there is a reduction in liability costs such as workmen's compensation claims.

\section{Limitations}

Telemental Health staff should be cognizant of some of the limitations to being located remotely. This includes potential challenges to accessing information that may be more readily available to onsite staff about activities of the facility. Events such as riots, racial tension, or suicides may adversely affect the mental and emotional condition of patients. Without the knowledge of these events and familiarity of the dynamics of the facility, telemental health staff may potentially be at a disadvantage from time to time. Nevertheless, these are not insurmountable obstacles. With proper communication and working relationships with onsite staff, telemental health clinicians can be kept abreast of important factors in the facility that can affect patients.

\section{Acknowledgments}

Funding: None.

\section{Footnote}

Conflicts of Interest: The author has completed the ICMJE uniform disclosure form (available at http://dx.doi. org/10.21037/mhealth.2019.12.05). EK reports other from null, outside the submitted work.

Ethical Statement: The author is accountable for all aspects of the work in ensuring that questions related to the accuracy or integrity of any part of the work are appropriately investigated and resolved.

Open Access Statement: This is an Open Access article distributed in accordance with the Creative Commons Attribution-NonCommercial-NoDerivs 4.0 International License (CC BY-NC-ND 4.0), which permits the non- 
commercial replication and distribution of the article with the strict proviso that no changes or edits are made and the original work is properly cited (including links to both the formal publication through the relevant DOI and the license). See: https://creativecommons.org/licenses/by-nc-nd/4.0/.

\section{References}

1. Serious Mental Illness Prevalence in Jails and Prisons. Treatment Advocacy Center. Sep 2016. [last accessed 7/24/19]. Available online: https://www.

treatmentadvocacycenter.org/evidence-and-research/

doi: $10.21037 /$ mhealth.2019.12.05

Cite this article as: Kaftarian E. Telemental health in rural correctional institutions. mHealth 2020;6:23. learn-more-about $/ 3695$

2. Estelle v. Gamble, 429 U.S. 97,97 S. Ct. 285, 50 L. Ed. 2d 251 (1976).

3. Sawyer W, Wagner P. Mass Incarceration: The Whole Pie 2019. Prison Policy Initiative. Mar 19, [last accessed 8/22/19]. Available online: https://www.prisonpolicy.org/ reports/pie2019.html

4. Eason J. Why prison building will continue booming in rural America. The Conversation. Mar 12, 2017.

5. Andrilla CHA, Patterson DG, Garberson LA, et al. Geographic Variation in the Supply of Selected Behavioral Health Providers. Am J Prev Med 2018;54:S199-207. 